\title{
Ultrasound-guided ropivacaine-driven pectoralis-blockage 1 to avoid significant and severe pain during pacemaker- implantation
}

\author{
Anger $T^{1 *}$, Pabst $\mathrm{P}^{1}$, Linnemann $\mathrm{S}^{1}$, Schneider $\mathrm{M}^{4}$, Jorbenadze $\mathrm{R}^{3}$, Oberhoff $\mathrm{M}^{1}$ and Döffert $\mathrm{J}^{2}$ \\ ${ }^{1}$ Department of Internal Medicine/Cardiology, Klinikum Calw-Nagold, Germany \\ ${ }^{2}$ Department of Anesthesiology, Klinikum Calw-Nagold, Germany \\ ${ }^{3}$ Department of Internal Medicine/Cardiology, University of Tübingen, Germany \\ ${ }^{4}$ Department of Electrophysiology, Klinikum Sindelfingen, Germany
}

\begin{abstract}
The implantation of cardiac devices (pacemakers) is often performed through invasive cardiologists under painful conditions for the patients lacking the knowledge of specific regional anesthesia. To rescue this situation, physicians are forced to use (i) sedation for the patients and (ii) tons of regional anesthesia like $500 \mathrm{mg}$ Prilocaine. We followed the idea of specific regional anaesthesia using ultrasound-guided pectoralis blockage 1 (PECS1 block: $10 \mathrm{ml}$ Ropivacaine $0.5 \%)$ and compared this approach with commonly used regional anesthesia on individuals with the indication for cardiac pacemaker implantation. We found significant less pain sensations using the PECS1 block during the operation procedure. US guided PECS1 block is a safe and completely useful tool in the Cath lab to proceed with cardiac device implantations.
\end{abstract}

\section{Introduction}

In general, local anesthesia is used to perform cardiac implantation procedures in the Cath lab. Thereby, invasive experienced cardiologists use up to 500mg Prilocaine or equivalent medication commonly for analgesia added to conscious sedation using Midalozam in combination with Fentanyl. Despite of sedation and local anesthesia, patients are still suffering pain during the implantation procedure (1): In the last study from Cambridge University, United Kingdom "Conscious sedation and analgesia use in cardiac device implantation, published 2013", on the assessed pain scale ( $0-10$, see below), all patients shortly asked after the implantation reach $3.4 \pm 2.1$ on the scale despite of age, co-morbidities or cardiac device implantation (pacemaker and cardiac resynchronization therapy implantation, elective unit replacements and pacing leads revision) [1]. The clinical meaning of this value is comparable with "moderate pain". Pain is additional stress for the patient with implanted cardiac device: The complex regional pain syndrome occurred in a few patients after pacemaker implantation [2,3] treated through steroids and neurotropin [4]. This stress may cause cardiomyopathy shortly after pacemaker implantation [5]. There is a need to abolish pain during cardiac device implantations increasingly carrying out in the Cath lab's world-wide.

Region of breast surgery is done in the same area: upper pectoral. Here, commonly the blockage of pectoral nerves known as Pectoralis Blockage (PECS block) is performed assessing thoracic pain-freeness over hours of duration [6-8]. The PECS block (pectoral nerves block) is an easy and reliable superficial block inspired by the infraclavicular block approach and the transversus abdominis plane blocks [7]. Once the pectoralis muscles are located under the clavicle the space between the two muscles is dissected to reach the lateral pectoral and the medial pectoral nerves [9]. The main indications were breast expanders and subpectoral prosthesis where the distension of these muscles is extremely painful. There is a variation of the PECS1 block divergent to the above described: PECS2 block. This PECS2 block aims to block at least the pectoral nerves, the intercostobrachial, intercostals III-IV$\mathrm{V}-\mathrm{VI}$ and the long thoracic nerve. These nerves need to be blocked to provide complete analgesia during breast surgery, and it is an alternative or a rescue block if paravertebral blocks and thoracic epidurals failed [8]. The search for the specific pectoral nerves will be achieved using Ultrasound (US) guiding, which is clearly favorable [9].

The combination of US-guided PECS block to gain pain-free operative assessment for cardiac implantation procedures is not established yet (10)-only a minor report of invasive cardiac surgery as case report exists $[10,11]$. Therefore, we focused our efforts to the specific use of US-controlled PECS1 block when cardiac devices were implanted. We followed the use of PECS1 block in a group of 50 consecutive patients with indication for cardiac implantations for pacemakers and we sampled age-matched a group of further nonrandomized consecutive 50 patients previously operated in the same Cath labs undergoing same procedure as control: implantation of pacemaker with common local anesthesia (up to 500mg Prilocaine). We assumed to abolish pain for the patients at all working in the regions of the pectoralis muscle which may in regard diminish stress shortly after the implantation procedure and may diminish stress-induced

*Correspondence to: Thomas Anger, Department of Internal Medicine/ Cardiology, Klinikum Calw-Nagold, Kliniken Calw, Germany, E-mail: t.anger@klinikverbund-suedwest.de

Key words: ultrasound, ropivacaine, pacemaker

Received: July 19, 2019; Accepted: July 26, 2019; Published: August 02, 2019 
cardiomyopathy [5]. We performed a multi-center, non-blinded study. Pain was questioned during the implantation procedure to evaluate the grade of pain on the pain scale (0-10) for all steps [1]. We grouped the patients and analyzed statistically the results (pain values) with convincing arguments for PECS1 block under US-guidance.

\section{Material and methods}

\section{Study population}

We collected $\mathrm{n}=50$ consecutive non-sedated patients with indication for pacemaker implantation (2-chamber pacemakers) to participate on this multi-center prospective study to test for PECS1 blockage and we asked verbally intraoperatively the study population for pain on different steps during the implantation procedure. All procedures were performed after written informed consent was obtained from patients according to the institutional guidelines at the "Klinikverbund Südwest Medical Center, Kliniken Calw". The study was approved by the institutional ethical review board of the "Klinikverbund Südwest". Klinikum Calw-Nagold/ Kliniken Calw, Germany is the responsible study side of this study. Intraoperatively, pain was assessed using a 10point pain scale (see below) [1]. We used this pain scale and compared the patients (PECS1) grouped to a novel regional anesthesia approach with none-sedated $n=50$ patients on sub-/intracutaneously applied local anesthesia using up to $500 \mathrm{mg}$ Prilocaine individually (also for implantation of a pacemaker), non-randomized and previously operated serving as control. Non-blinded, we compared the two different approaches of local anesthesia procedures while the implantation procedure itself was set to an established cardiac approach without any divergences of the procedure [12]. No further sedation was applied for the patient during the operation procedure. The PECS1 block was performed by the experienced invasive cardiologist.

\section{Pain-scale}

We used a pain scale going from 0 as no pain at all up to 10 as maximal possible pain ever imagined for the patient - published recently [1].

\section{Ultrasound-controlled local anesthesia}

Pectoralis Blockage [7] Using a Philips Affinity $50 \mathrm{C}$ with linear array $12-4 \mathrm{MHz}$ or a Sonosite S-Nerve with a 6-13 MHz linear probe, we marked medio-thoracic both muscles, pectoralis major and minor, respectively and controlled application of $20 \mathrm{ml}$ Ropivacaine $0.5 \%$ (needle system, round tip, non-sharp: Payunk uniplex nanoline $22 \mathrm{Gx} 50 \mathrm{~mm}$ ) between both muscles near the Morheim' poach to realize anesthesia of the nerves in between the muscles, according to Blanco et al. [7]. This procedure was safe, no complication occurred, was well tolerated and no patient got hurt. Prior to the Pectoralis Blockage (PECS1 block), we performed moderate skin anesthesia using 100mg Prilocain (4G needle, sharp tip). In the control group, we decided individually to use $200 \mathrm{mg}$ Prilocaine for the skin, for intraand subcutaneous infiltration to reduce pain for the puncture of the vena subclavia as well as we used at least $250 \mathrm{mg}$ Prilocaine intra- and subcutaneously for the port-preparation, the plug-in of the device and the fixation of the sleeves on the muscle pectoralis major, in general.

\section{Implantation procedure}

This operative procedure was established and performed in the Cath labs of the involved study sites (Sindelfingen, Calw, Tübingen). All steps were performed in sterile conditions. There are 6 steps to follow to implant a cardiac pacemaker device as cardiologist in the Cath lab [12]. In general, here in our hands, the location of the pacemaker is left thoracic subcutaneous. Subsequently, 6 established steps will follow immediately always under same conditions in accordance to the Pocket trial, 2017 [12]. After each step, we asked the patient for pain according the described pain scale [1].

Step 1: The intravenous puncture of the vena subclavia outside of the Thorax through the anesthetized skin and under contrast medium enhanced perfusion of the vena subclavia to avoid pneumothoraxes during pacemaker implantation procedure in the Cath lab. Subsequently, both probes (first right ventricle, then right atrium) were placed and fixed immediately under X-ray assessment.

Step 2: The skin cut to prepare the subfascial pocket for the pacemaker device ( 2.5 to $3 \mathrm{~cm}$ length). Preparation of the subcutaneous place up to the fascia of the muscle pectoralis major [12].

Step 3: The attachment of the sleeves by sewing primarily of suture material in the muscle of pectoralis major and by a second circular sewing of the sleeves on the pacemaker-probes to fix these probes and to avoid the Twiddler syndrome $[1,12]$.

Step 4: The preparing of the pocket for the device. Thereby, manually, with an established two-finger system, the pocket (subfascial) as landing zone for the pacemaker device will be prepared and this procedure is dramatically painful without adjusted regional anesthesia. This is only a short step - nevertheless very painful $[1,12]$.

Step 5: The insertion of the device into the prepared pocket which is dramatically painful. Also, in contrast to the step before, no difference in the experience of pain must be set $[1,12]$.

Step 6: The skin closure by sewing in two steps, a subcutaneous sew procedure and an intra-cutaneous step to close safely the skin and to avoid bacterial contaminations. The whole procedure takes $45 \mathrm{~min}$ and it was performed through the same experienced cardiologist always in the same manner on each study side. X-ray was used to demonstrate correctness of the probe locations and to rule out pneumothoraxes during the procedure.

\section{Statistical analysis}

We collected grade of pain using the pain scale from 0 to 10 on every step. Data represent mean \pm SEM as indicated. We analyzed the pain values using unpaired student t-tests for significance in regard to the Bonferroni correction and age-matched groups. A p value $<0.008$ was considered statistically significant and marked directly in the graphs.

\section{Results}

\section{Study population}

We collected $n=50$ consecutive none-sedated patients for the group with ultrasound-controlled PECS1 block in comparison to age-matched $n=50$ none-sedated patients previously operated with up to maximal 500mg Prilocaine for common regional anesthesia left thoracically in regard to implant a pacemaker device in the Cath lab. Overall, the ultrasound-guided Pectoralis Blockage (PECS1) using $100 \mathrm{mg}$ Prilocaine in combination to $10 \mathrm{ml}$ Ropivacaine $0.5 \%$ was well tolerated and no complications (pericardial effusion, pneumothorax requiring chest drain insertion, severe wound hematoma, or lead displacement requiring reposition) were seen, nor in the other group. The demographic characteristics of the both groups were similar, no statistically differences were to observe: the mean age [\# \pm Standard Error of the mean] of the enrolled patients was $68 \pm 3$ years, 38\% males, $62 \%$ females, indications were similar in both groups: sick sinus 
syndrome $28 \%$, bradyarrhythmia $34 \%$, any av blockage $24 \%$, syncope with two-bundle bunch block or two-nodular disease in combination $14 \%$. The incidence of cardiac diseases was similar in both groups, only minor patients had known coronary artery disease (13\%), but all enrolled patients had normal left ventricular function. The procedure duration was quite different: $45 \pm 5 \mathrm{~min}$ for regional anesthesia, 55 \pm 5 min for additional PECS1 blockage (statistically not significant). Radiation duration was similar in both groups: $2 \pm 0,5 \mathrm{~min}$.

\section{Pain scale data}

We performed a 6 steps procedure (12) established in one experienced invasive cardiologist's hand on each study site and we assessed sustained experience of pain by having questioned a pain scale value for each of the 6 steps during the procedure (Figures 1-6). Clearly and remarkable demonstrated in Figure 3-5, we observed some statistically significant differences between the experience of pain during the implantation procedure using PECS1 block (marked as group 2) in comparison to common 500mg Prilocaine local anesthesia (marked as group 1), p-value below 0.008 (Bonferroni correction assumed). The first steps (the puncture of the vena subclavia, the skin cut) as well as the last step: the skin closure, both were very well tolerated, and no further murmur was observed between both groups. The experience of pain was similar in both groups for these 3 steps since the observer (experienced invasive cardiologists) had used Prilocaine for skin anesthesia. For the 3 steps associated with the pectoralis muscle, there is a clear advantage using PECS1 block to abolish pain in contrast to Prilocaine supported anesthesia (Figures 3-5). The ultrasound-guided application of Ropivacaine between the muscles pectoralis major and minor was safe

\section{Puncture}

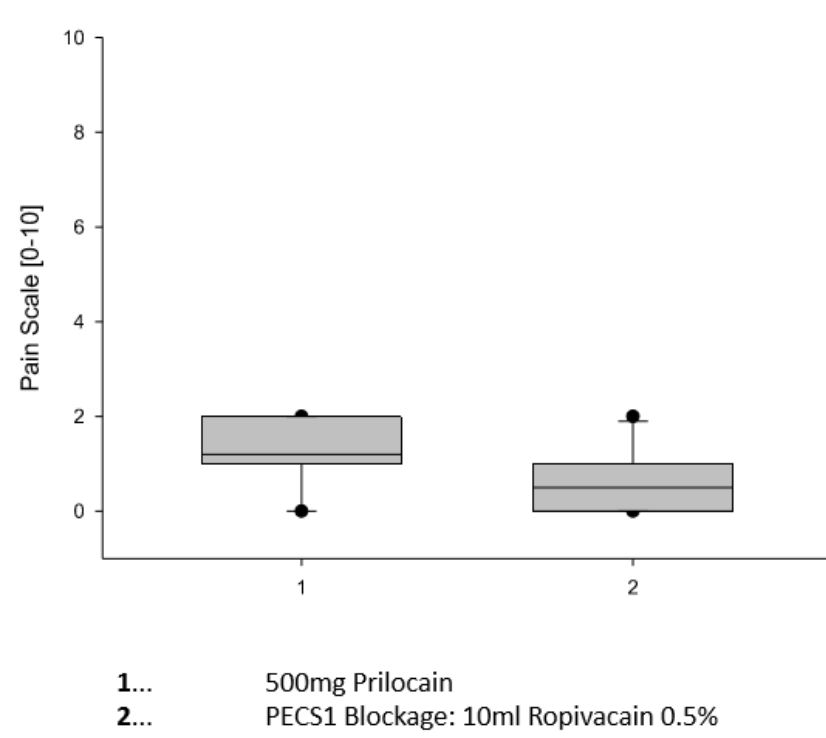

Figure 1. Comparison of Regional Anesthetic Efforts on the Puncture of the Vena subclavia. Shown here is step 1 of the Pacemaker-Implantation Procedure: the intravenous puncture of the vena subclavia outside of the Thorax to avoid pneumothoraxes during pacemaker implantation procedure in the Cath lab. The Comparison shows the use of 500mg Prilocain (1) subcutaneously and intracutaneously perfused prior to procedure to avoid pain for the patient and the use of $100 \mathrm{mg}$ Prilocain intracutaneously given in combination with ultrasound-guided application of $10 \mathrm{ml}$ Ropivacain $0.5 \%$ between the two pectoralis muscles minor and major, respectively, under the regional anesthetic approach: PECS1 blockage (2). Data are presented as mean (line) \pm SEM (bar), as well as the $5 \%$ and $95 \%$ confidence interval. When eligible, statistical significance was marked with the written $\mathrm{p}$-value in the graph

\section{Cut}

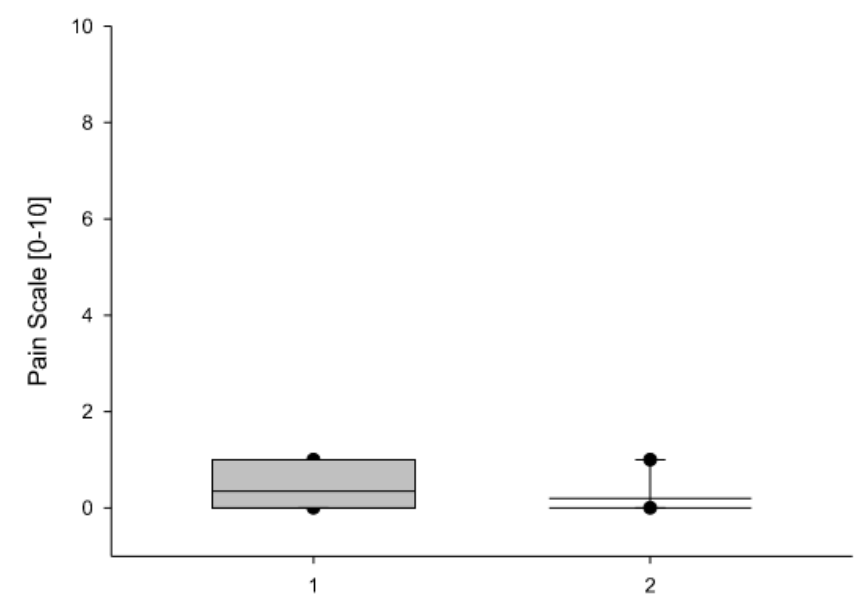

Figure 2. Comparison of Regional Anesthetic Efforts on the Skin Cut. Shown here is step 2 of the Pacemaker-Implantation Procedure: the skin cut to prepare the subfascial port for the pacemaker device. The Comparison shows the use of 500mg Prilocain (1) subcutaneously and intracutaneously perfused prior to procedure to avoid pain for the patient and the use of $100 \mathrm{mg}$ Prilocain intracutaneously given in combination with ultrasound-guided application of $10 \mathrm{ml}$ Ropivacain $0.5 \%$ between the two pectoralis muscles minor and major respectively: the PECS1 blockage (2). Data are presented as mean (line) \pm SEM (bar), as well as the $5 \%$ and $95 \%$ confidence interval. When eligible, statistical significance was marked with the written p-value in the graph

\section{Sleaves Fixation on the Muscle}

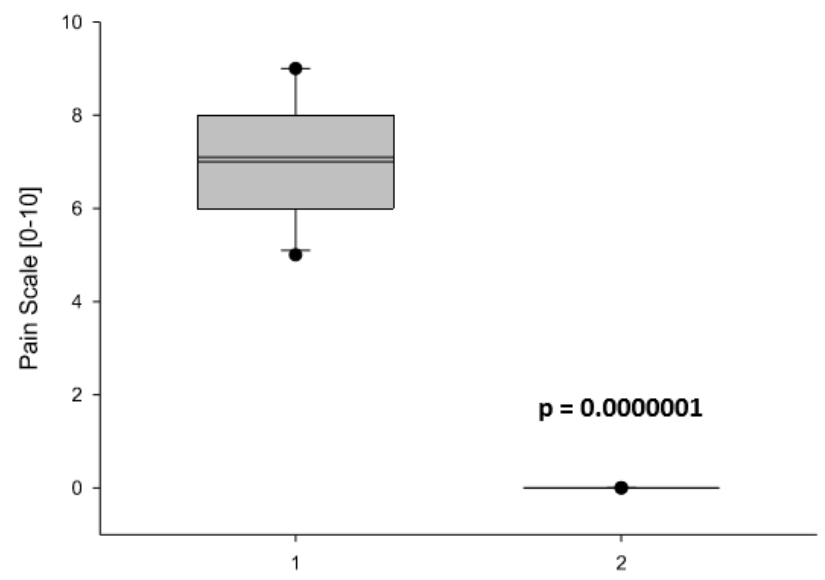

Figure 3. Comparison of Regional Anesthetic Efforts on the Fixation of the Sleeves. Shown here is step 3 of the Pacemaker-Implantation Procedure: the attachment of the sleeves by sewing primarily of suture material in the muscle of Pectoralis major and by a second circular sewing of the sleeves on the pacemaker-probes to fix these probes and to avoid the Twiddler syndrome. The Comparison shows the use of 500mg Prilocain (1) subcutaneously and intracutaneously perfused prior to procedure to avoid pain for the patient and the use of $100 \mathrm{mg}$ Prilocain intracutaneously given in combination with ultrasound-guided application of $10 \mathrm{ml}$ Ropivacain $0.5 \%$ between the two pectoralis muscles minor and major respectively: the PECS1 blockage (2). Data are presented as mean (line) \pm SEM (bar), as well as the $5 \%$ and $95 \%$ confidence interval. When eligible, statistical significance was marked with the written p-value in the graph

and lead to pain-free conditions during the implantation. Ultrasound control was safe itself, no infection occurred, no pneumothorax or no probe dislocation was observed in regard to the implantation in both groups. The duration of the implantation procedure was prolonged, but 
not statistical relevant: mean of $45 \pm 5$ min for the commonly fashioned regional anesthesia, $55 \pm 5$ min for the Pectoralis Blockage supported procedure.

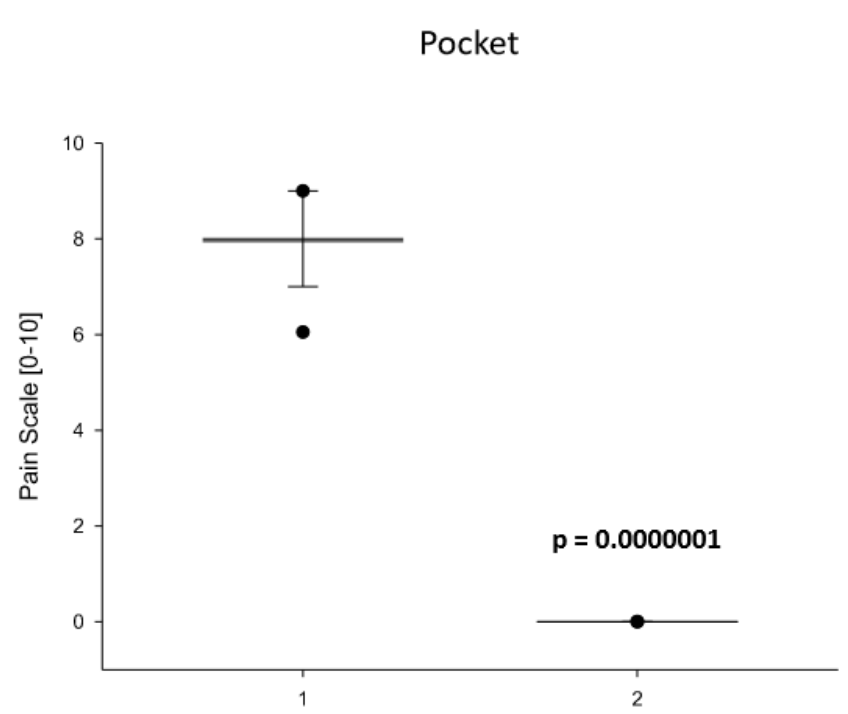

Figure 4. Comparison of Regional Anesthetic Efforts on Preparing of the Pocket for the Device. Shown here is step 4 of the Pacemaker-Implantation Procedure: the preparing of the pocket for the device. Thereby, manually, with an established two-finger system, the port as landing zone for the pacemaker device will be prepared and this procedure is dramatically painful without adjusted regional anesthesia. The Comparison shows the use of 500mg Prilocain (1) subcutaneously and intracutaneously perfused prior to procedure to avoid pain for the patient and the use of $100 \mathrm{mg}$ Prilocain intracuntaneously given in combination with ultrasound-guided application of $10 \mathrm{ml}$ Ropivacain $0.5 \%$ between the two pectoralis muscles minor and major, respectively: the PECS1 blockage (2). Data are presented as mean (line) \pm SEM (bar), as well as the $5 \%$ and $95 \%$ confidence interval. When eligible, statistical significance was marked with the written p-value in the graph

\section{Insertion of the Device into the Pocket}

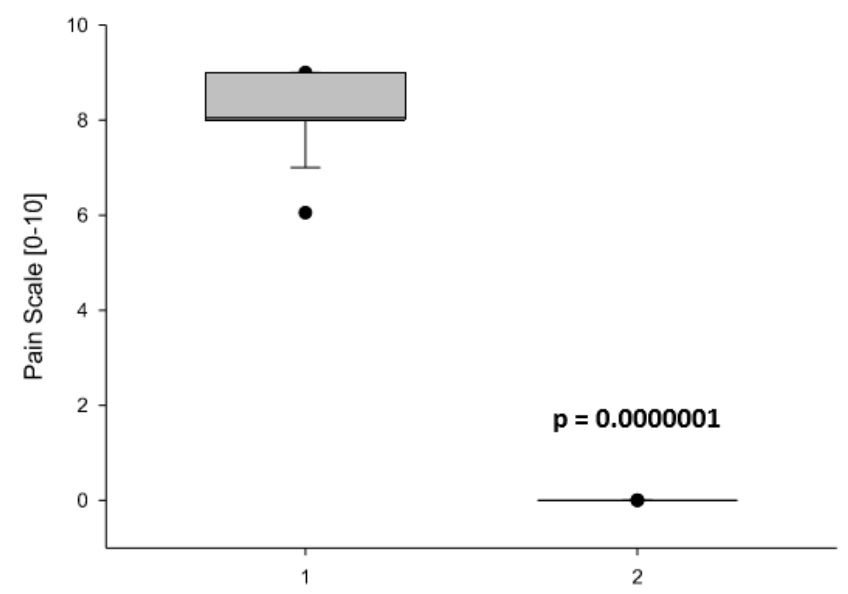

Figure 5. Comparison of Regional Anesthetic Efforts on Insertion of the Device into the Pocket. Shown here is step 5 of the Pacemaker-Implantation Procedure: the insertion of the device into the prepared pocket which is dramatically painful. The Comparison shows the use of 500mg Prilocain (1) subcutaneously and intracutaneously perfused prior to procedure to avoid pain for the patient and the use of $100 \mathrm{mg}$ Prilocain intracuntaneously given in combination with ultrasound-guided application of $10 \mathrm{ml}$ Ropivacain $0.5 \%$ between the two pectoralis muscles minor and major, respectively: the PECS1 blockage (2). Data are presented as mean (line) \pm SEM (bar), as well as the $5 \%$ and $95 \%$ confidence interval. When eligible, statistical significance was marked with the written p-value in the graph
Skin Closure

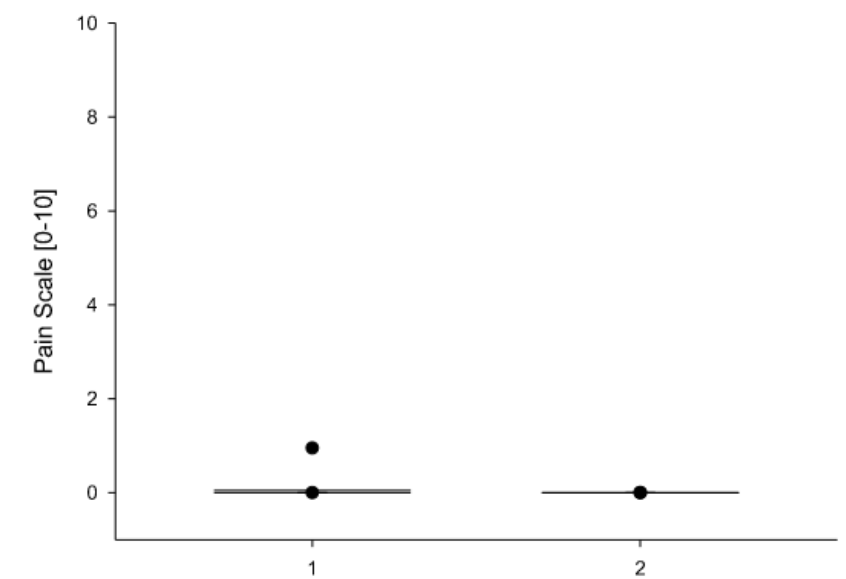

Figure 6. Comparison of Regional Anesthetic Efforts on the Skin Closure by sewing. Shown here is the last step 6 of the Pacemaker-Implantation Procedure: the skin closure by sewing in two steps, a subcuntaneous sew procedure and an intracutaneous step to close safely the skin and to avoid bacterial contaminations. The Comparison shows the use of $500 \mathrm{mg}$ Prilocain (1) subcutaneously and intracutaneously perfused prior to procedure to avoid pain for the patient and the use of $100 \mathrm{mg}$ Prilocain intra-cutaneously given in combination with ultrasound-guided application of $10 \mathrm{ml}$ Robivacain $0.5 \%$ between the two pectoralis muscles minor and major, respectively: the PECS1 blockage (2). Data are presented as mean (line) \pm SEM (bar), as well as the $5 \%$ and $95 \%$ confidence interval. When eligible, statistical significance was marked with the written p-value in the graph

\section{Discussion}

Pain is an issue during pacemaker implantation operations in the Cath lab worldwide. Since pacemakers are fixed on the pectoralis muscle [12], experienced invasive cardiologists are enforced to abolish pain associated with the procedure steps in respect to maintain the direct involvement of the muscle during the implantation. Sedation will not abolish this specific procedure dependent pain [1]. Additionally, pain will cause stress leading to cardiomyopathy for a few patients without any predictors to avoid it shortly after pacemaker implantations [5]. Also, there is the complex regional pain syndrome occurring in a few patients after pacemaker implantation [2,3] treatable through Steroids and Neurotropin [4]. So, there is need to abolish pain at all during the pacemaker implantation procedure. We first and primarily used ultrasound-guided infiltration of Ropivacaine between the pectoralis muscles major and minor as PECS1 block, the blockage of pectoral nerves (Figure 7) for pain-free implantation of cardiac devices (here: pacemakers) in the Cath lab as novel type of regional anesthesia for invasive and experienced cardiologists. This procedure of regional anesthesia is clearly safe, no further complications were outstanding, and the procedure was quick. We matched the groups to age and used only 2 -chamber pacemaker implantation procedures to dismanage bias problems through the implantation technique itself. We only used nonesedated patients to be crucial to the method of the regional anesthesia. We performed a multi-center, non-blinded, non-randomized study since the nature of the anesthesia itself would be unexpecting in its quality under sedation conditions. Blinding for statistical study reasons would diminish the interobserver variability - but with conscious, nonsedated patients blinding in the maintenance of pain is not working out efficiently. Realistically, the preparation of the pocket for the device, the fixation of the sleeves on the muscle pectoralis major and the insertion of the device into the pocket are extremely painful procedure steps 

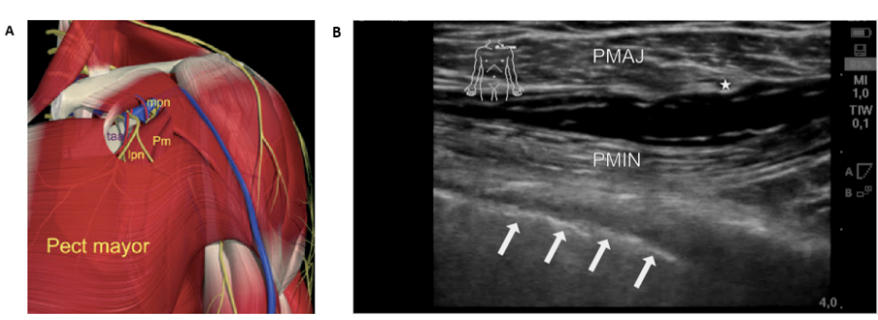

Figure 7. Schematic Graph and Ultrasound Picture to demonstrate location of Ropivacain application: Pectoralis Blockage 1 (7). Graphic representation (A) of the anatomical area of injection under the pectoralis major muscle. Under the upper part of pectoralis minor $(\mathrm{Pm})$, the pectoral branch of the thoracoacromial artery (taa) is easily identified with the lateral pectoral nerve (lpn) adjacent to it. At that level, the medial pectoral nerve (mpn) is underneath the minor pectoral nerve. (CPrimal Pictures, www.primalpictures.com/ - graph cited from (7)). (B) Shown here is an example for the region of interest to apply $10 \mathrm{ml}$ Ropivacain $0,5 \%$ as regional anesthesia between the muscles pectoralis minor (marked with PMIN) and major (marked with PMAJ) and to assess the Pectoralis Blockage 1 for painfree thoracic work as done for subfascial device implantation in the Cath lab through the invasive cardiologist. * marks the pectoral branch of the thoraco-acromial artery, arrows are demonstrating the pleura

for all patients and in general [12], only sedation may barely cure this situation [1]. No further intra-/subcutaneous infiltration will be helpful to diminish this pain. The PECS1 block abolishes this pain completely.

The new technique (Pectoralis Blockage: PECS1 block) is rare used und performed. Only a small numbers of Case reports are published, i.e. [13-15] next to a bunch of publications about local/ regional anesthesia using PECS1 block for breast surgery $[6,16]$. No specific publication exists for the use of PECS1 block under the idea of regional anesthesia performing subfascial cardiac device implantations [10], other than one publication for minimal invasive cardiac surgery [11]. First in man, breast surgery lead to the development of Pectoralis Blockage according to the pectoral nerves and their block $[7,17]$. There is no further doubt to clearly assess the PECS block using ultrasound-control [9]. In the past, in regard to breast surgery, Blanco et al. described therefore 2 ways of blockage: PECS1 [7] and PECS2 [8]. PECS1 is performed as described above. The PECS1 block (pectoral nerves block 1) is an easy and reliable superficial block inspired by the infraclavicular block approach and the transversus abdominis plane blocks [7]. Once the pectoralis muscles are located under the clavicle the space between the two muscles is dissected to reach the lateral pectoral and the medial pectoral nerves. The main indications were breast expanders and subpectoral prosthesis where the distension of these muscles is extremely painful. A second version of the Pecs block is described subsequently through Blanco et al, 2012, called "modified Pecs block" or Pecs block type II: PECS II. This almost new approach aims to block at least the pectoral nerves, the intercostobrachial, intercostals III-IV-V-VI and the long thoracic nerve. These nerves need to be blocked to provide complete analgesia during breast surgery, and it is an alternative or a rescue block if paravertebral blocks and thoracic epidurals failed [8].

In regard to the toxicity of local anesthetics initially regional infiltrated with later systemic perfusion for anesthesia (here: Prilocaine), several complications are described doses-dependent $[18,19]$ : epileptic attacks, cardiac arrest, neurogenic shocks, loss of consciousness, agitation and more. It is necessary for safety reasons not to exceed more then $5 \mathrm{mg} / \mathrm{kg}$ Prilocaine during the procedure in regard to the opportunity for systemic transformation of the Prilocainein our hands: some of the patients were near the upper cutoff of this dosage [20]. Here, we exclusively used PECS1 Block for the cardiac implantation procedure and we were successful using ultrasound as control/ guide. The PECS1 block abolish nearly all pain for the patients during the operation steps associated with the pectoralis muscle [12].
It doesn't seem necessary to use PECS2 block since we didn't fail for analgesia in our region of interest: left thoracic pectoral subfascial area. The data encourage experienced invasive cardiologists to use the PECS1 block for cardiac device implantation procedures - probably despite of the operative technique maintained [11].

\section{Conclusion}

Here, our data exclusively demonstrates the statistically significant specific use of US-guided Ropivacaine infiltration into the space between the thoracic muscles pectoralis major and minor-known as PECS1 block (pectoralis nerves blockage 1) to assume pain-free cardiac device implantation without general anesthesia for all operation steps in association with the pectoralis muscle. We are clearly supporting advantages (pain-freeness) and safety (no complications) for a novel method, routinely used in our Cath labs. The use of the ultrasound controlled PECS1 block with Ropivacaine must held entrance to all operative cardiac procedures made under defined conditions for regional anesthesia.

Further studies must follow to abolish the skin infiltration (intra-/ sub-cutaneous) to reduce the amount of unspecific infiltrated Prilocaine and to further reduce pain for these patients in the Cath lab - since on the pain scale, we are not starting with "none pain" at the beginning of the operative cardiac procedure.

\section{References}

1. Looi KL, Lee AS, Cole K, Agarwal S, Heck PM, et al. (2013) Conscious sedation and analgesia use in cardiac device implantation. Int J Cardiol 168: 561-563. [Crossref]

2. Kisanuki M, Fujita K, Moriyama S, Irie K, Yosida C, et al. (2017) Complex regional pain syndrome induced by pacemaker implantation for sick sinus syndrome. $J$ Arrhythm 33: 643-645. [Crossref]

3. Kamath S, Rao BS (2015) Complex regional pain syndrome type I following pacemaker implantation. Indian Heart J 3: 103-106. [Crossref]

4. Okada M, Suzuki K, Hidaka T, Shinohara T, Kataharada K, et al. (2002) Complex regional pain syndrome type I induced by pacemaker implantation, with a good response to steroids and neurotropin. Intern Med 41: 498-501. [Crossref]

5. Dias A, Franco E, Usatii V (2013) Stress-induced cardiomyopathy shortly after pacemaker placement. J Invasive Cardiol 25: 207-209. [Crossref]

6. Bashandy GM, Abbas DN (2015) Pectoral nerves I and II blocks in multimodal analgesia for breast cancer surgery: a randomized clinical trial. Reg Anesth Pain Med 40: 68-74. [Crossref]

7. Blanco R (2011) The 'pecs block': a novel technique for providing analgesia after breas surgery. Anaesthesia 66: 847-848. [Crossref]

8. Blanco R, Fajardo M, Parras Maldonado T (2012) Ultrasound description of Pecs II (modified Pecs I): a novel approach to breast surgery. Rev Esp Anestesiol Reanim 59: 470-475. [Crossref]

9. Abrahams M, Derby R, Horn JL (2016) Update on Ultrasound for Truncal Blocks: A Review of the Evidence. Reg Anesth Pain Med 41: 275-288. [Crossref]

10. Miller MA, Bhatt HV, Weiner M, Brouwer TF, Mittnacht AJ, et al. (2018) Implantation of the subcutaneous implantable cardioverter-defibrillator with truncal plane blocks. Heart Rhythm 15: 1108-1111. [Crossref]

11. Yalamuri S, Klinger RY, Bullock WM, Glower DD, Bottiger BA, et al. (2017) Pectoral Fascial (PECS) I and II Blocks as Rescue Analgesia in a Patient Undergoing Minimally Invasive Cardiac Surgery. Reg Anesth Pain Med 42: 764-766. [Crossref]

12. Magnusson P, Wennstrom L, Kastberg R, Liv P (2017) Placement Of Cardiac PacemaKEr Trial (POCKET) - rationale and design: a randomized controlled trial. Heart Int 12: e8-e11. [Crossref]

13. Ueshima H, Hiroshi, Otake (2017) Transcatheter aortic valve implantation performed with a PECS block and a TTP block. J Clin Anesth 38: 1. [Crossref]

14. Ueshima H, Hiroshi O (2017) Optimal site of administration of the PECS 1 block. $J$ Clin Anesth 38: 82. [Crossref] 
Anger T (2019) Ultrasound-guided ropivacaine-driven pectoralis-blockage 1 to avoid significant and severe pain during pacemaker-implantation

15. Ueshima H, Otake H (2017) Ultrasound-guided pectoral nerves (PECS) block: Complications observed in 498 consecutive cases. J Clin Anesth 42: 46. [Crossref]

16. Moon EJ, Kim SB, Chung JY, Song JY, Yi JW (2017) Pectoral nerve block (Pecs block) with sedation for breast conserving surgery without general anesthesia. Ann Surg Treat Res 93: 166-169. [Crossref]

17. Chakraborty A, Khemka R, Datta T, Mitra S (2016) COMBIPECS, the single-injection technique of pectoral nerve blocks 1 and 2: a case series. J Clin Anesth 35: 365-368. [Crossref]
18. Zink W, Sinner B, Zausig Y, Graf BM (2007) Myotoxicity of local anaesthetics: experimental myth or clinical truth?. Anaesthesist 56: 118-127. [Crossref]

19. Guay J (2009) Adverse events associated with intravenous regional anesthesia (Bier block): a systematic review of complications. J Clin Anesth 21: 585-594. [Crossref]

20. Gitman M, Barrington MJ (2018) Local Anesthetic Systemic Toxicity: A Review of Recent Case Reports and Registries. Reg Anesth Pain Med 43: 124-130. [Crossref]

Copyright: @2019 Anger T. This is an open-access article distributed under the terms of the Creative Commons Attribution License, which permits unrestricted use, distribution, and reproduction in any medium, provided the original author and source are credited. 